\title{
Naphthyl azomesogens with lateral chloro groups ${ }^{\dagger}$
}

\author{
A K PRAJAPATI*, H M PANDYA and N L BONDE \\ Applied Chemistry Department, Faculty of Technology and Engineering, M S University of Baroda, \\ Kalabhavan, P O Box No 51, Vadodara 390 001, India \\ e-mail: akprajapati@yahoo.co.uk
}

MS received 15 October 2003; revised 11 June 2004

\begin{abstract}
A homologous series of azomesogens, 2"-[4-(4'-n-alkoxybenzoyloxy)-2-chlorophenylazo] naphthalenes, with lateral chloro groups was synthesised. All the homologues synthesized exhibit enantiotropic nematic mesophase. The mesomorphic properties of the present series are compared with other structurally related series to evaluate the effect of lateral chloro group and its position on mesomorphism.
\end{abstract}

Keywords. Azomesogens; lateral chloro group; nematic.

\section{Introduction}

A vast number of mesogenic naphthalene derivatives are reported in the literature, ${ }^{1,2}$ as naphthalene derivatives exhibit rich mesomorphism if properly designed. Wiegand ${ }^{3}$ reported a few mesogenic Schiff bases of 2,6-, 1,5- and 1,4-diaminonaphthalenes. Gray and Jones ${ }^{4}$ investigated liquid crystalline properties of different alkoxynaphthoic acids. Coates and Gray $^{5}$ synthesized 4- $n$-alkyl/alkoxy phenyl esters of 6-n-alkyl/alkoxy naphthalene 2-carboxylic acid. Dave and others studied a variety of liquid crystalline naphthalene derivatives such as alkoxybenzoates of 1,5- and 1,4-dihydroxynaphthalene, ${ }^{6}$ esters of cholesterol $^{7}$ and alkoxy naphthylidene Schiff's bases ${ }^{8-10}$ exhibiting smectic, nematic, and cholesteric mesomorphism. Malthete $e t a l^{11}$ synthesized tetra-acylated 1,4,5,8-tetrahydroxynaphthalene derivatives, which may be looked upon as "conjoined twin" mesogens. In the last decade, a significant number of research papers on naphthalene LC cores appeared in the literature. ${ }^{12-21}$ Recently the synthesis and mesomorphic properties of banana-shaped compounds derived from 2,7-dihydroxynaphathalene have also appeared in the literature. ${ }^{22,23}$ Previously we have reported $^{24,25}$ the mesogenic homologous series of Schiff's base esters containing the naphthalene moiety and studied the effect of lateral thiol and methoxy

\footnotetext{
This paper was presented at the 10th National Conference on Liquid Crystals held at Bangalore, India during 9-11 October 2003.

*For correspondence
}

substituent on mesomorphism. We have also reported the synthesis of mesogenic homologous series of azomesogens without lateral substituent, ${ }^{26}$ with lateral methyl ${ }^{27}$ and chloro ${ }^{28}$ groups and evaluated the effect of lateral methyl as well as chloro group on mesomorphism. Recently, we have reported ${ }^{29}$ the mesogenic homologous series of azoesters containing two naphthalene nucleuses and studied the effect of naphthalene moiety on mesomorphism. We have also reported ${ }^{30}$ mesogenic homologous series of Schiff's base cinnamates comprising a naphthalene moiety and investigated the effect of an ethylene linking group (cinnamoyl linkage) and naphthalene moiety on the mesomorphic properties of such molecules. As an extension of this work on naphthalene moiety, we have synthesized a new mesogenic homologous series of azoesters containing lateral chloro group to investigate the influence of the lateral chloro group and its position on mesomorphism.

\section{Experimental}

\subsection{Characterization}

Microanalysis of the compounds was performed on a Coleman carbon-hydrogen analyzer and the values obtained are in close agreement with those calculated. IR spectra were determined as $\mathrm{KBr}$ pellets, using a Shimadzu IR-408 spectrophotometer. ${ }^{1} \mathrm{H}$ NMR spectra were obtained with a Perkin-Elmer R-32 spectrometer using tetramethylsilane (TMS) as internal reference standard. The chemical shifts are 

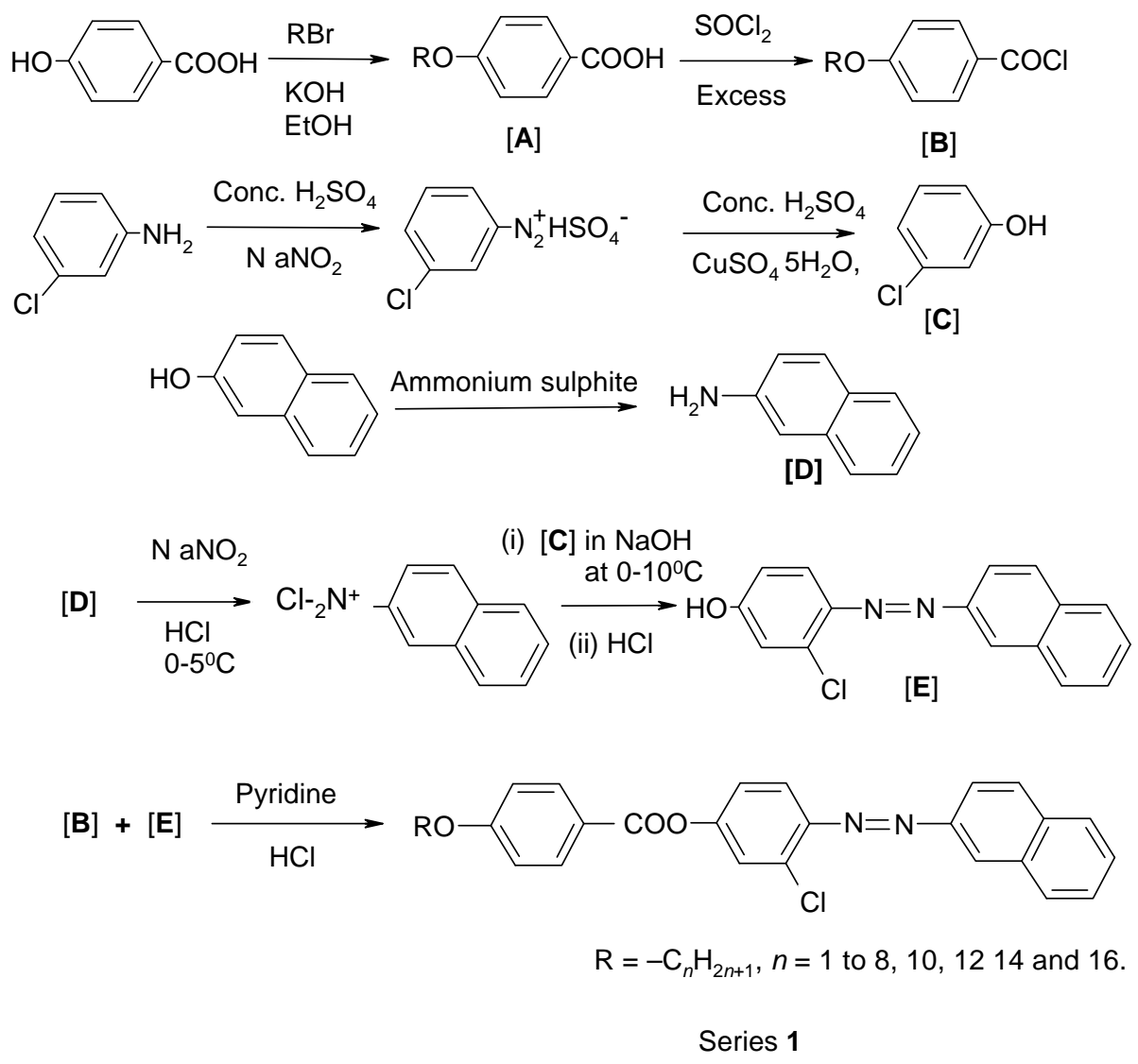

Scheme 1. Synthetic route to series 1.

quoted as $\delta$ (parts per million) downfield from the reference. $\mathrm{CDCl}_{3}$ was used as a solvent for all the compounds. Liquid crystalline properties were investigated on a Leitz Laborlux 12 POL microscope provided with a heating stage. The enthalpies of transitions reported as $\mathrm{J} / \mathrm{g}$, were determined from thermo grams obtained on a Mettler TA-4000 system, adopting a scanning rate of $5^{\circ} \mathrm{C} / \mathrm{min}$. The calorimeter was calibrated using pure indium as standard.

\subsection{Synthesis}

The synthetic route to series $\mathbf{1}$ and $\mathbf{2}$ is illustrated in scheme 1.

4-Hydroxybenzoic acid, the appropriate $n$-alkyl halides, $\mathrm{SOCl}_{2}, \mathrm{KOH}$, 2-naphthol, 3-chloro aniline, $\mathrm{NaNO}_{2}, \mathrm{CuSO}_{4} 5 \mathrm{H}_{2} \mathrm{O}$, anhydrous $\mathrm{K}_{2} \mathrm{CO}_{3}$ etc. were used as received. Solvents were dried and distilled prior to use.

2.2a 4-n-Alkoxybenzoic acids [A] and 4-nalkoxybenzoyl chlorides $[B]$ : These were synthesized by the modified method of Dave and Vora. ${ }^{31}$ 2.2b 3-Chlorophenol [C]: Two similar methods $^{32,33}$ are convenient for the synthesis of 3-chlorophenol. However the first method ${ }^{32}$ permits the use of copper sulphate pentahydrate after diazotization of 3 -chloroaniline ${ }^{33}$ and gives somewhat better yield.

A solution of $(54 \mathrm{~g})$ of 3-chloroaniline in $83 \mathrm{ml}$ of conc. $\mathrm{H}_{2} \mathrm{SO}_{4}$ and $150 \mathrm{ml}$ of water was cooled by addition of $250 \mathrm{~g}$ of ice and diazotized with $27.3 \mathrm{~g}$ of $\mathrm{NaNO}_{2}$ in $54 \mathrm{ml}$ of water. The filtered solution of the diazonium salt was added dropwise to a mixture of water $(175 \mathrm{ml})$, sulphuric acid $(170 \mathrm{ml}, d 1 \cdot 84)$, and copper sulphate pentahydrate $(50 \mathrm{~g})$ which was steam-distilled. The temperature of the diazotized solution was kept below $5^{\circ} \mathrm{C}$ until immediately before the addition. Extraction of the distillate with ether, followed by distillation, gave the phenol $(70 \%$ yield), b.p. $211^{\circ} \mathrm{C}$, deliquescent yellow needles, m.p. $31^{\circ} \mathrm{C}$ (reported ${ }^{32}$ m.p. $31-32^{\circ} \mathrm{C}$ ).

2.2c 2-Aminonaphthalene [D]: The 2-aminonaphthalene was synthesized by following the method described in the literature. ${ }^{34} \mathrm{~A}$ stream of sulphur dioxide was passed into $200 \mathrm{ml}$ of cooled, concen- 
trated ammonia solution (sp. gr. 0.88) until $50 \mathrm{~g}$ of gas was absorbed. This ammonium sulphite solution was placed together with $72 \mathrm{~g}$ of 2-naphthol in an autoclave provided with a stirrer and stirring adjusted at $260 \mathrm{rpm}$. The mixture was securely fastened in the cap and heated at $150^{\circ} \mathrm{C}$ with continuous stirring for $8 \mathrm{~h}$. It was then allowed to cool with stirring. The reaction mixture was then removed from the apparatus diluted with the aid of about $250 \mathrm{ml}$ of water and filtered on a Buckner funnel. The crude material was dissolved in a boiling mixture of $75 \mathrm{ml}$ of concentrated hydrochloric acid and $200 \mathrm{ml}$ of water, and then diluted with $500 \mathrm{ml}$ of water. Five grams of decolourizing carbon was added, the solution boiled for $5 \mathrm{~min}$, and filtered through a hot water funnel to remove any undissolved dinapthylamine $\left(\mathrm{C}_{10} \mathrm{H}_{7} \mathrm{NHC}_{10} \mathrm{H}_{7}\right)$. The hot filtrate was poured with stirring into a solution of $60 \mathrm{~g}$ of sodium hydroxide in $250 \mathrm{ml}$ of water. It was ensured that the resulting slurry was alkaline to phenolphthalein, cooled with stirring to $20^{\circ} \mathrm{C}$, filtered with suction, and washed with 11 of cold water. It was then pressed well. The product was dried to constant weight at $50-60^{\circ} \mathrm{C}$. Yield of 2-aminonaphthalene, m.p. $112^{\circ} \mathrm{C}$ (reported ${ }^{34}$ m.p. $112-113^{\circ} \mathrm{C}$ ) isolated as a light tan powder was $55 \%$.

$2.2 \mathrm{~d} 2-\left(4^{\prime}-\right.$ Hydroxy-2'-chlorophenylazo) naphthalene $[E]$ : 2-(4'-Hydroxy-2'-chlorophenylazo) naphthalene was synthesis by using conventional method of diazotization and coupling. ${ }^{34}$ The dye was crystallized from ethanol till constant melting point was obtained. Yield: $68 \%$ m.p. $138^{\circ} \mathrm{C}$. Elemental analysis: found $\mathrm{C} 68.06, \mathrm{H} 3 \cdot 23, \mathrm{~N} 9.46 \%, \mathrm{C}_{16} \mathrm{H}_{11} \mathrm{~N}_{2} \mathrm{Cl}$ requires C $68.21, \mathrm{H} 3 \cdot 55, \mathrm{~N} 9.94 \%$. IR spectra of the compound show a broad peak of intermolecularly hydrogen bonded phenolic $-\mathrm{OH}$ between 3500 and $3100 \mathrm{~cm}^{-1} .-\mathrm{N}=\mathrm{N}-$ stretching vibrations are seen at $1605 \mathrm{~cm}^{-1}$. Other signals are observed at 1500, 1465, $1380,1230,1150,850,686(\mathrm{C}-\mathrm{Cl}) \mathrm{cm}^{-1}$.

2.2e 2"-[4-(4'-n-(Alkoxybenzoyloxy)-2-chlorophenylazo]naphthalenes (1): 2-(4'-Hydroxy-2'-chlorophenylazo) naphthalene $(0.02 \mathrm{~mol})$ was dissolved in dry pyridine $(5 \mathrm{ml})$ and a cold solution of $4-n$-alkoxybenzoyl chloride $(0.02 \mathrm{~mol})$ in dry pyridine was added with constant stirring in an ice bath. The mixture was allowed to stand overnight at room temperature. It was acidified with cold water and hydrochloric acid. The solid obtained was separated, dried and triturated by stirring for 30 min with $10 \%$ aqueous sodium hydroxide, and was then washed with water. The insoluble mass separated and crystallized several times from acetic acid till constant transition temperatures were obtained. Yield: 65 to $70 \%$. Elemental analysis of all compounds of series 1 was found to be satisfactory and the compounds are listed in table 1.

IR spectrum ( $n$-tetradecyloxy derivative): 2900, 1735 (-COO-) , 1604, $1581(-\mathrm{N}=\mathrm{N}-)$ 1510, 1470, $1400,1220,898,850,750,690\left(\mathrm{C}-\mathrm{Cl} \mathrm{cm}^{-1}\right)$.

${ }^{1} \mathrm{H}$ NMR spectrum (n-tetradecyloxy derivative, $200 \mathrm{MHz}): \delta 0.88\left(t, 3 \mathrm{H},-\mathrm{CH}_{3}\right), 1 \cdot 26-1.85(m, 24 \mathrm{H}$, $\left.12 \mathrm{X}-\mathrm{CH}_{2}-\right), 4.05\left(t, 2 \mathrm{H}, \mathrm{ArOCH}_{2}\right), 7.00(d$, $J=9 \mathrm{~Hz}, 2 \mathrm{H}, \mathrm{ArH}$ at C-3' and C-5'), 7.20-7.60 (m, $7 \mathrm{H}$, ArH of naphthalene ring), 7.80-7.95 $(\mathrm{m}, 2 \mathrm{H}$, ArH at C-5 and C-6), 8.00-8.15 ( $m, 2 \mathrm{H}, \mathrm{ArH}$ at C-2' and $\left.\mathrm{C}-6^{\prime}\right), 8 \cdot 50(s, 1 \mathrm{H}, \mathrm{ArH}$ at $\mathrm{C}-3)$.

Table 1. Elemental analysis for series 1 compounds.

\begin{tabular}{lccccc}
\hline & & & \multicolumn{3}{c}{ \% Required (\% found) } \\
\cline { 4 - 6 } Compound & $\mathrm{R}=-\mathrm{C}_{n} \mathrm{H}_{2 n+1} n=$ & Formula & $\mathrm{C}$ & $\mathrm{H}$ & $\mathrm{N}$ \\
\hline $\mathbf{1}$ & 1 & $\mathrm{C}_{24} \mathrm{H}_{17} \mathrm{~N}_{2} \mathrm{O}_{3} \mathrm{Cl}$ & $69 \cdot 15(69 \cdot 24)$ & $4 \cdot 08(3 \cdot 81)$ & $6 \cdot 72(6 \cdot 57)$ \\
$\mathbf{2}$ & 2 & $\mathrm{C}_{25} \mathrm{H}_{19} \mathrm{~N}_{2} \mathrm{O}_{3} \mathrm{Cl}$ & $69 \cdot 69(69 \cdot 71)$ & $4 \cdot 41(4 \cdot 67)$ & $6 \cdot 50(6 \cdot 45)$ \\
$\mathbf{3}$ & 3 & $\mathrm{C}_{26} \mathrm{H}_{21} \mathrm{~N}_{2} \mathrm{O}_{3} \mathrm{Cl}$ & $70 \cdot 19(70 \cdot 06)$ & $4 \cdot 72(4 \cdot 92)$ & $6 \cdot 30(6 \cdot 21)$ \\
$\mathbf{4}$ & 4 & $\mathrm{C}_{27} \mathrm{H}_{23} \mathrm{~N}_{2} \mathrm{O}_{3} \mathrm{Cl}$ & $70 \cdot 67(70 \cdot 55)$ & $5 \cdot 02(4 \cdot 86)$ & $6 \cdot 12(6 \cdot 37)$ \\
$\mathbf{5}$ & 5 & $\mathrm{C}_{28} \mathrm{H}_{25} \mathrm{~N}_{2} \mathrm{O}_{3} \mathrm{Cl}$ & $71 \cdot 11(71 \cdot 42)$ & $5 \cdot 29(5 \cdot 38)$ & $5 \cdot 93(6 \cdot 06)$ \\
$\mathbf{6}$ & 6 & $\mathrm{C}_{29} \mathrm{H}_{27} \mathrm{~N}_{2} \mathrm{O}_{3} \mathrm{Cl}$ & $71 \cdot 53(71 \cdot 26)$ & $5 \cdot 55(5 \cdot 58)$ & $5 \cdot 75(5 \cdot 92)$ \\
$\mathbf{7}$ & 7 & $\mathrm{C}_{30} \mathrm{H}_{29} \mathrm{~N}_{2} \mathrm{O}_{3} \mathrm{Cl}$ & $71 \cdot 93(72 \cdot 17)$ & $5 \cdot 79(5 \cdot 84)$ & $5 \cdot 59(5 \cdot 54)$ \\
$\mathbf{8}$ & 8 & $\mathrm{C}_{31} \mathrm{H}_{31} \mathrm{~N}_{2} \mathrm{O}_{3} \mathrm{Cl}$ & $72 \cdot 30(71 \cdot 95)$ & $6 \cdot 02(6 \cdot 37)$ & $5 \cdot 44(5 \cdot 24)$ \\
$\mathbf{9}$ & 10 & $\mathrm{C}_{33} \mathrm{H}_{35} \mathrm{~N}_{2} \mathrm{O}_{3} \mathrm{Cl}$ & $72 \cdot 99(72 \cdot 73)$ & $6 \cdot 45(6 \cdot 66)$ & $5 \cdot 16(5 \cdot 18)$ \\
$\mathbf{1 0}$ & 12 & $\mathrm{C}_{35} \mathrm{H}_{39} \mathrm{~N}_{2} \mathrm{O}_{3} \mathrm{Cl}$ & $73 \cdot 62(73 \cdot 46)$ & $6 \cdot 84(6 \cdot 85)$ & $4 \cdot 91(4 \cdot 82)$ \\
$\mathbf{1 1}$ & 14 & $\mathrm{C}_{37} \mathrm{H}_{43} \mathrm{~N}_{2} \mathrm{O}_{3} \mathrm{Cl}$ & $74 \cdot 18(74 \cdot 38)$ & $7 \cdot 18(7 \cdot 26)$ & $4 \cdot 68(4 \cdot 77)$ \\
$\mathbf{1 2}$ & 16 & $\mathrm{C}_{37} \mathrm{H}_{47} \mathrm{~N}_{2} \mathrm{O}_{3} \mathrm{Cl}$ & $74 \cdot 70(74 \cdot 86)$ & $7 \cdot 50(7 \cdot 21)$ & $4 \cdot 47(4 \cdot 80)$ \\
\hline
\end{tabular}




\section{Results and discussion}

Mesophases exhibited by series 1 compounds were identified by examining thin films of a sample sandwiched between a glass slide and a cover slip under a optical polarizing microscope. On cooling the isotropic liquid small droplets appeared which coalesce to classical schlieren (threaded) textures characteristic of the nematic phase.

Calorimetry is a valuable method for the detection of phase transitions. It yields quantitative results; therefore we may draw conclusions concerning the nature of the phases which occur during the transitions. In the present study, enthalpies of two derivatives of each series 1 were measured by differential scanning calorimetry. Data are recorded in table 2. Enthalpy values of the various transitions agree well with the literature ${ }^{35}$ value.

\subsection{Series 1-2"'-[4(4'-n-alkoxybenzoyloxy) 2-chlo- rophenylazo]naphthalenes}

All the twelve homologues synthesised exhibit enantiotropic nematic mesophase (table 3). It can be noticed from the plot of transition temperatures against the number of carbon atoms (figure 1) that crystal-mesophase transition temperatures decrease with increase in the length of terminal alkoxy chain with the exception of $n$-propyloxy, $n$-butyloxy and $n$-octyloxy derivatives. The N-I transition temperatures also decrease with increase in terminal alkoxy tail and exhibit the usual odd-even effect. However the odd-even effect of this series is not so pronounced. This is in agreement with the observation reported for such homologues series. ${ }^{36}$

Table 4 shows the comparison of $\mathrm{N}$-iso transition temperature, range (width) of nematic phase and molecular structure of representative compound 7 $(n=7)$ of the present series $\mathbf{1}$ and structurally related compounds $\mathrm{A}^{28}, \mathrm{~B}^{26}, \mathrm{C}^{27}$ and $\mathrm{D}^{29}$ reported in the literature. The nematic mesophase range and the $\mathrm{N}$-iso transition temperature of compound $\mathbf{7}$ are

Table 2. DSC data for series 1 compounds.

\begin{tabular}{lccrrr}
\hline Series & $n=$ & Transition & $\begin{array}{c}\text { Peak tempe- } \\
\text { rature }\left({ }^{\circ} \mathrm{C}\right)\end{array}$ & \multicolumn{1}{c}{$\Delta H$} & \multicolumn{1}{c}{$\Delta S$} \\
\hline $\mathbf{1}$ & \multirow{2}{*}{12} & $\mathrm{Cr}-\mathrm{N}$ & $91 \cdot 6$ & $22 \cdot 90$ & $0 \cdot 0628$ \\
& & $\mathrm{~N}-\mathrm{I}$ & $152 \cdot 5$ & $1 \cdot 17$ & $0 \cdot 0027$ \\
& \multirow{2}{*}{14} & $\mathrm{Cr}-\mathrm{N}$ & $92 \cdot 2$ & $45 \cdot 07$ & $0 \cdot 1234$ \\
& & $\mathrm{~N}-\mathrm{I}$ & $139 \cdot 6$ & 1.05 & $0 \cdot 0025$ \\
\hline
\end{tabular}

lower by $4.0^{\circ} \mathrm{C}$ and $47 \cdot 0^{\circ} \mathrm{C}$, respectively when compared with of compound $\mathbf{B}$. The molecular structure of compound $\mathbf{7}$ differs from compound $\mathbf{A}$ only at the central aromatic core; compound $\mathbf{7}$ has lateral chloro group at the central benzene nucleus, whereas compound $\mathbf{B}$ has no lateral substituent at the central benzene nucleus. Thus compared with the molecule of compound $\mathbf{B}$, the molecule of compound $\mathbf{7}$ has increased breadth due to the lateral chloro group on central benzene ring. Gray ${ }^{36}$ has explained that increase in the breadth of the molecules reduces both nematic and smectic mesophase stability. It seems that the lateral chloro group not only increases the breadth of the molecule of compound 7 but also in-

Table 3. Transition temperatures $\left({ }^{\circ} \mathrm{C}\right)$ of the series $\mathbf{1}$.

$\mathrm{R}=-\mathrm{C}_{n} \mathrm{H}_{2 n+1}$

\begin{tabular}{|c|c|c|c|c|c|c|}
\hline Compound & $n=$ & $\mathrm{Cr}$ & & $\mathrm{N}$ & & I \\
\hline 1 & 1 & $\bullet$ & 103 & $\bullet$ & 216 & $\bullet$ \\
\hline 2 & 2 & $\bullet$ & 98 & $\bullet$ & 215 & $\bullet$ \\
\hline 3 & 3 & • & 107 & • & 204 & • \\
\hline 4 & 4 & $\bullet$ & 135 & $\bullet$ & 205 & $\bullet$ \\
\hline 5 & 5 & $\bullet$ & 95 & - & 188 & • \\
\hline 6 & 6 & $\bullet$ & 94 & $\bullet$ & 179 & $\bullet$ \\
\hline 7 & 7 & - & 92 & • & 171 & • \\
\hline 8 & 8 & $\bullet$ & 95 & $\bullet$ & 165 & $\bullet$ \\
\hline 9 & 10 & $\bullet$ & 92 & $\bullet$ & 158 & • \\
\hline 10 & 12 & $\bullet$ & 89 & $\bullet$ & 153 & $\bullet$ \\
\hline 11 & 14 & $\bullet$ & 89 & $\bullet$ & 150 & $\bullet$ \\
\hline 12 & 16 & $\bullet$ & 87 & $\bullet$ & 148 & $\bullet$ \\
\hline
\end{tabular}

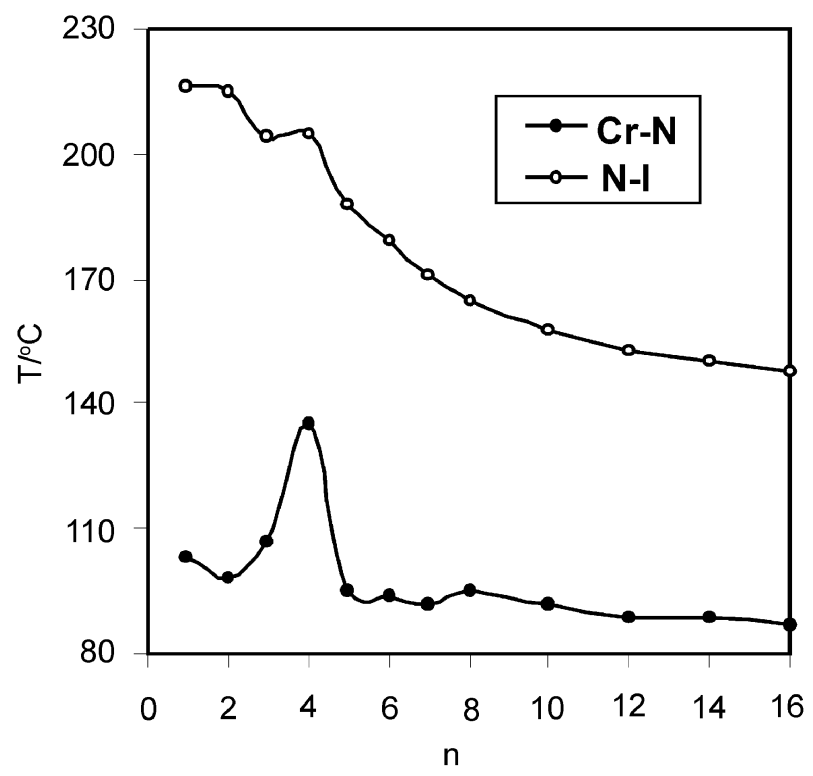

Figure 1. The phase behaviour of series $\mathbf{1}$. 
Table 4. The comparison of $\mathrm{N}$-iso transition temperature $\left({ }^{\circ} \mathrm{C}\right)$ and the range of nematic phase between a representative compound $7\left(\mathrm{C}_{7}\right.$ homologue) of the present series $\mathbf{1}$ and structurally related compounds reported in the literature.

$\mathrm{R}=-\mathrm{C}_{7} \mathrm{H}_{15}$, comparative molecular structure of the compounds $7, \mathbf{A}, \mathbf{B}, \mathbf{C}$ and $\mathbf{D}$.

\begin{tabular}{|c|c|c|c|c|c|c|c|}
\hline Compound & $\mathrm{Cr}$ & & $\mathrm{N}$ & & Iso & $\begin{array}{c}\text { Mesophase } \\
\text { range ( C) }\end{array}$ & $\begin{array}{l}\text { Commencement of } \\
\text { smectic phase }\end{array}$ \\
\hline 7 & • & $92 \cdot 0$ & - & $171 \cdot 0$ & - & $79 \cdot 0$ & - \\
\hline $\mathbf{A}$ & • & $111 \cdot 0$ & • & $186 \cdot 0$ & • & $75 \cdot 0$ & - \\
\hline B & • & $135 \cdot 0$ & • & $218 \cdot 0$ & - & 83.0 & $\mathrm{C}_{10}$ \\
\hline C & • & $86 \cdot 0$ & • & $147 \cdot 0$ & - & $61 \cdot 0$ & - \\
\hline D & $\bullet$ & $111 \cdot 0$ & - & $144 \cdot 0$ & - & $33 \cdot 0$ & - \\
\hline
\end{tabular}<smiles>[R]Oc1ccc(C(=O)Oc2ccc(N=Nc3ccc4ccccc4c3)c(Cl)c2)cc1</smiles>

Compound 7<smiles>[R]Oc1ccc(C(=O)Oc2ccc(N=Nc3ccc4ccccc4c3)cc2Cl)cc1</smiles>

Compound A<smiles>[R]Oc1ccc(C(=O)Oc2ccc(/N=N/c3ccc4ccccc4c3)cc2)cc1</smiles>

Compound B<smiles>[R]Oc1ccc(C(=O)Oc2ccc(N=Nc3ccc4ccccc4c3)c(C)c2)cc1</smiles>

Compound $\mathbf{C}$

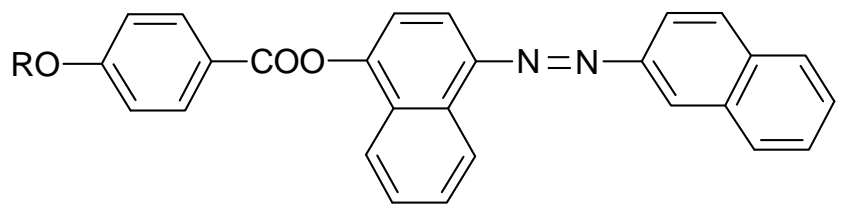

Compound D

creases the acoplanarity in the system due to stearic interaction. Both these factors would eliminate the smectogenic tendencies as well as decrease the nematic mesophase range and the $\mathrm{N}$-iso transition temperature for compound 7 reported in the present investigation. These agree well with the work reported by Prajapati ${ }^{27}$ in which the mesogenic homologous series $\mathrm{C}$ with a lateral methyl group exhibits only nematic phase with low thermal stabilities compared to parent unsubstituted homologous series B.

Reference to table 4 indicates that the width of the nematic mesophase for compound $\mathbf{A}$ is $75.0^{\circ} \mathrm{C}$ and for compound 7 is $79 \cdot 0^{\circ} \mathrm{C}$, whereas $\mathrm{N}$-iso transition temperature for compound $\mathbf{A}$ is $186 \cdot 0^{\circ} \mathrm{C}$ and that of compound 7 is $171 \cdot 0^{\circ} \mathrm{C}$. Gray ${ }^{36}$ has explained that a compound which requires more thermal energy to disorganize the parallel molecular arrangement of the nematic melt is thermally more stable. As can be seen in table 4, more thermal energy has to be supplied to disorganize the parallel molecular arrangement of the nematic melt of compound $\mathbf{A}$, as can be evidenced by the fact that the $\mathrm{N}$-iso transition temperature is higher by $15.0^{\circ} \mathrm{C}$, than for compound 7. The higher N-iso transition temperature for compound A may be due to the presence of lateral chloro group ortho to the - $\mathrm{COO}$ - central linkage. Probably the flexibility of the - $\mathrm{COO}$ - central linkage compensates the stearic hindrance and enables a 
more compact packing of the molecules to stabilize the nematic. The range and thermal stability of the mesophase is a more important factor in relating mesomorphic behaviour to chemical constitution, since the chemical grouping gives rise to intermolecular attractions which in turn determine the mesophase range and thermal stability. One should remember too that the length of the mesophase is determined partly by the $\mathrm{Cr}-\mathrm{N}$ transition temperature, which is lower for compound 7 compared to compound A. Therefore the nematic mesophase length for compound 7 is higher by $4 \cdot 0^{\circ} \mathrm{C}$ than that of compound $\mathbf{A}$.

Table 4 shows that the nematic mesophase range and the $\mathrm{N}$-iso transition temperature for compound 7 are higher by $18.0^{\circ} \mathrm{C}$ and $24.0^{\circ} \mathrm{C}$ respectively, when compared to that of compound $\mathbf{C}$. The difference in the molecular structure of both the compounds is only in the type of lateral substituent on the central benzene nucleus. Compound $\mathbf{7}$ has a lateral chloro group, whereas compound $\mathbf{C}$ has a lateral methyl group. Probably the increase in the polarizability of the compound $\mathbf{7}$ due to polar chloro group slightly overcomes the increased molecular separation caused by the lateral substituent. Therefore, the width of the nematic mesophase as well as the $\mathrm{N}$-iso transition temperature of compound $\mathbf{7}$ becoming a little higher than that of compound $\mathbf{B}$.

Table 4 further shows that the nematic mesophase range as well as $\mathrm{N}$-iso transition temperature of compound 7 are higher by $46 \cdot 0^{\circ} \mathrm{C}$ and $27.0^{\circ} \mathrm{C}$ respectively, when compared to that of compound $\mathbf{D}$. The molecular structural difference between compounds $\mathbf{7}$ and $\mathbf{D}$ lies only at the central aromatic core; compound $\mathbf{7}$ has lateral chloro groups at the central benzene nucleus, whereas compound $\mathbf{D}$ has a naphthalene nucleus at the centre. This difference has significant influence on the nematic mesophase range as well as on $\mathrm{N}$-iso transition temperature as can be seen in table 4 . The stabilization of nematic phase in case of compound 7 is wide and perhaps the foregoing discussion would hold good for this behaviour.

From the above discussion the order of lateral group efficiency for nematic phase thermal stability can be derived for the compounds as under: $-\mathrm{H}>3-$ $\mathrm{Cl}>2-\mathrm{Cl}>-\mathrm{CH}_{3}>$ fused ring (1-4 substituted naphthalene moiety).

It agrees well with the order in lateral group efficiency for nematic phase obtained by Gray $^{36}$ for pure nematogenic rod-shaped molecules.

\section{Conclusion}

A new mesogenic homologous series of naphthyl azomesogens with lateral chloro groups was synthesized. The study indicated that the lateral chloro group adversely affects mesophase thermal stability. However, due to the polar nature of the chloro group, the effect is less pronounced compared to the lateral methyl group.

\section{Acknowledgements}

The authors thank Prof S M Joshi, and Dr N D Jadav for encouragement.

\section{References}

1. Demus D and Zaschke H 1984 Flussige Kristalle in Tabllen II (Leipzig: VEB Deutscher Verlag fur Grundstoffindustrie)

2. Vill V 1996 Liq. Cryst. 2.0-Database of liquid crystalline compounds for personal computers, Fijitsu Kyushu System (KQS) Ltd., Fukuoka 1996. (Hamburg: $\mathrm{LCl}$ )

3. Wiegand C Z 1954 Naturforschung B9 516

4. Gray G W and Jones B 1954 J. Chem. Soc. 638; Gray G W and Jones B 1955 J. Chem. Soc. 236

5. Coates D and Gray G W 1978 Mol. Cryst. Liq. Cryst. 41197

6. Dave J S, Kurian G and Joshi B C 1980 Liq. Cryst.: Proc. Int. Conf. (ed.) S Chandrasekhar (London: Heyden) 549

7. Dave J S and Kurian G 1977 Mol. Cryst. Liq. Cryst. 42 193; Dave J S and Kurian G 1975 Pramana 1427

8. Dave J S, Kurian G, Prajapati A P and Vora R A 1971 Mol. Cryst. Liq. Cryst. 14 307; 1972 Curr. Sci. 41 415; 1972 Indian J. Chem. 10754

9. Dave J S and Prajapati A P 1975 Pramana 1735

10. Dave J S, Kurian G and Prajapati A P 1983 Mol. Cryst. Liq. Cryst. 99385

11. Malthete J, Billard J, Jacques $\mathrm{J}$ and Rhebald C S 1975 Acad. Sci., Paris C 281333

12. Wedler W, Demus D, Zaschke H, Mohr K, Schafer K W and Weissflog W 1991 J. Mater. Chem. 1347

13. Mochizuki A, Motoyoshi K and Nakatsuka M 1991 Ferroelectrics 12237

14. Sierra T, Serrano J L, Rose M B, Ezcurra A and Zubia J 1992 J. Am. Chem. Soc. 1147645

15. Marcos M, Omenat A, Serrano J L, Sierra T and Ezcurra A 1992 Adv. Mater. 4285

16. Hird M, Toyne K J and Gray G W 1993 Liq. Cryst. 14741

17. Ganzalez Y, Ros M B, Serrano J L and Perezjubind A 1995 Liq. Cryst. 18751

18. Bhatt J C, Keast S S, Neubert M E and Petscheks R G 1995 Liq. Cryst. 18367 
19. Suste A, Moslavac D and Sunjic V 1996 Liq. Cryst. 21383

20. Sadashiva B K and Gropalakrishnan C R 1998 Macromol. Rapid Commum. 1997

21. Wu S-L and Hsieh W-J 1999 Chem. Mater. 11852

22. Reddy R A and Sadashiva B K 2000 Liq. Cryst. 27 1613

23. Thisayukta J, Kamee H, Kawauchi S and Watanabe J 2000 Mol. Cryst. Liq. Cryst. 34663

24. Vora R A and Prajapati A K 1999 Liq. Cryst. 25 567

25. Prajapati A K 2000 Mol. Cryst. Liq. Cryst. 34865

26. Vora R A and Prajapati A K 1996 Proceeding of the $V$ National Seminar on Liquid Crystals, Patiala, p. 97

27. Prajapati A K 2000 Liq. Cryst. 271017

28. Prajapati A K and Pandya H M 2003 Mol. Cryst. Liq. Cryst. 39331
29. Jadav N D, Prajapati B A and Prajapati A K 2003 Mol. Cryst. Liq. Cryst. (in press)

30. Prajapati A K, Thakkar V and Bonde N 2003 Mol. Cryst. Liq. Cryst. 9341

31. Dave J S and Vora R A 1970 Liquid crystals and ordered fluids (eds) J F Johnson and R S Porter (New York: Plenum) p. 477

32. Acheson R M and Taylor N F 1956 J. Chem. Soc. 51 4727

33. Fieser L F and Thompson H T $1939 \mathrm{~J}$. Am. Chem. Soc. 61382

34. Vogel A I 1951 Textbook of practical organic chemistry 2nd ed. (London: ELBS and Longmann) pp. 547, 946

35. Marzotko D and Demus D 1975 Pramana 1189

36. Gray G W 1962 Molecular structure and properties of liquid crystals (London and New York: Academic Press) 